\title{
O LÉXICO DO PORTUGUÈS SOB O OLHAR de Gaetano Osculati: ELEMENTOS DA FAUNA E FLORA
}

\author{
BenILde Socreppa SchultZ*
}

RESUMO: O Rio Amazonas e sua imensa bacia hidrográfica ladeada por imponentes florestas, sempre exerceram um fascínio imenso em todos que ouviram falar dele. Desde o seu descobridor Vincente Pinzón, que em 1500 denominou-o de Rio Santa Maria del Mar Dulce, até os dias de hoje, aventureiros, biólogos, cartógrafos, geógrafos, indianistas e muitos outros cientistas percorreram suas águas à procura de informações que pudessem explicar a grandiosidade dessa obra da natureza. O fascínio do Rio-mar atraiu também o viajante italiano Gaetano Osculati, que em 26 de outubro de 1847 começou a sua viagem em canoa pelo Rio Napo, cuja nascente está no Equador, nas proximidades do monte Cotopaxi, e foz no Rio Solimões. Gaetano Osculati, espelhando-se em Orellana, faz o mesmo e ao final da sua viagem de quatro anos, escreve Esplorazioni delle Regioni Equatoriali lungo il Napo ed il fiume delle Amazzoni, publicado em Milão no ano de 1854, o qual utilizamos para recolher o léxico português inserido incidentalmente ou voluntariamente na obra. Ao escrever sobre o que observava, na falta de termos em italiano, o explorador se apropria de novas palavras, transcrevendo-as da maneira como as ouviu. Normalmente, há, nas nomeações existentes no interior da narrativa, uma estreita ligação entre o nomear e o narrar: ao nomear, o narrador concentra na palavra uma série de sinais linguísticos, a sua carga cultural, o seu saber e sua capacidade expressiva. Pretendemos, neste artigo, à luz das teorias de

\footnotetext{
* Universidade Estadual do Oeste do Paraná, Cascável (Brasil) - perbeni @ gmail.com
} 
Alves (1990; 2010), Klajn (1972) e Nunes (1996), recolher, registrar e classificar os empréstimos lexicais do português e do tupi, na obra de Gaetano Osculati, com o objetivo de contribuir para o estudo da Lexicologia histórica portuguesa e italiana, em especial recuperar os empréstimos lexicais portugueses utilizados pelo viajante italiano.

PALAVRAS-CHAVE: Gaetano Osculati; viajantes italianos; neologismos do português.

ABSTRACT: Il Fiume delle Amazzoni e il suo grande bacino idrografico fiancheggiato da imponenti foreste hanno sempre esercitato un'immensa seduzione su tutti coloro che ne hanno sentito parlare. Sin dal suo scopritore Vincente Pinzón, che nel 1500 lo chiamò Rio Santa Maria del Mar Dulce, ad oggi, avventurieri, biologi, cartografi, geografi, indigenisti e tanti altri scienziati hanno cercato le sue acque per ottenere informazioni che avrebbero potuto spiegare la grandiosità di quest'opera della natura. Il fascino del Fiume-Mare ha anche attirato l'attenzione del viaggiatore italiano Gaetano Osculati, che il 26 ottobre 1847 ha iniziato il suo viaggio in canoa sul fiume Napo, uno dei tributari del fiume delle Amazzoni, la cui sorgente è situata all'Equatore. Gaetano Osculati, che si riflette in Orellana, fa lo stesso, e al termine del suo viaggio di quattro anni compilò il libro Esplorazioni delle Regioni Equatoriali lungo il Napo ed il fiume delle Amazzoni, pubblicato a Milano nel 1854, di cui abbiamo raccolto il lessico portoghese inserito incidentalmente o volontariamente nell'opera. Scrivendo di ciò che ha osservato, in assenza di termini in italiano, l'esploratore si avvale di nuove parole, trascrivendole nel modo in cui le ha ascoltate. Di solito si osserva, all'interno della narrazione, una stretta connessione tra il denominare e il narrare: al nominare, il narratore concentra sulla parola una serie di segni linguistici, la sua carica culturale, la sua conoscenza e la sua capacità espressiva. In questo articolo, alla luce delle teorie di Alves (1990, 2010), Klajn (1972), Nunes (1996), ci proponiamo di raccogliere, registrare e classificare i prestiti lessicali nell'opera di Gaetano Osculati, per poter contribuire allo studio della lessicologia storica portoghese e italiana e in particolare per recuperare i prestiti lessicali portoghesi utilizzati dal viaggiatore italiano.

PAROLE-CHIAVE: Gaetano Osculati; viaggiatori italiani; neologismi del portoghese. 
ABSTRACT: The Amazon River and its huge watershed, lined with imposing forests, have always fascinated everyone who has heard of it. From its discoverer Vincente Pinzón, who in 1500 named it the Rio Santa Maria del Mar Dulce, until these days, adventurers, biologists, cartographers, geographers, indianists and many other scientists have searched its waters for information that could explain the grandeur of this work of nature. The fascination of this Sea-River also attracted the Italian traveler Gaetano Osculati, who on October 261847 began his canoe trip along the Napo River-which has its source in Ecuador near Mount Cotopaxi and empties into the Rio Solimões. Gaetano Osculati, mirroring himself in Orellana, does the same, and at the end of his four-year journey writes Esplorazioni delle Regioni Equatoriali lungo il Napo ed il fiume delle Amazzoni, published in Milan in 1854, from which we collected the Portuguese lexicon inserted incidentally or voluntarily in the book. When writing about what he observed, in the absence of terms in the Italian language, the explorer uses new words, transcribing in the way he hears them. Usually, there is a close connection between naming and narrating in the narrative: in naming, the narrator concentrates on the word a series of linguistic signs, their cultural charge, their knowledge and their expressive capacity. In this article, in light of the theories by Alves (1990; 2010), Klajn (1972 and Nunes (1996), we intend to collect, register and classifythe lexical loans of Portuguese and Tupi in the work of Gaetano Osculati, with the main aim of contributing to the study of the Portuguese and Italian historical lexicology, and in particular to recover the Portuguese lexical loans used by the Italian traveler.

KEYWORDS: Gaetano Osculati; Italian travelers; neologisms of Portuguese. 


\section{Introdução}

leque formado por rios que convergem do Equador, Peru, Colômbia, Bolívia e Brasil se articula em uma rede de artérias que se conjugam no coração da Amazônia formando o corpo do mais caudaloso, misterioso e cobiçado rio do planeta. Vicente Yanes Pinzon, ao descobri-lo tão imenso na sua foz, o denominou de Santa Maria del Mar Dulce e, desde então, povoou o imaginário de viajantes e cientistas que o exploraram na tentativa de desvendar seus mistérios.

O primeiro a cumprir essa etapa foi Francisco Orellana, que o percorreu, não por curiosidade, mas por necessidade, pois a expedição da qual participava, organizada por Gonzalo Pizarro, irmão de Francisco Pizarro, dividiu-se. A expedição que partiu de Quito em 1541 não se interessava pelo Amazonas, queria conquistar terras para a coroa espanhola, apossar-se das florestas de canela e ir à procura de ouro e do lendário Eldorado, que segundo diziam, abundava 
na região. Para Anthony Smith (1990, p.62) “o objetivo era riqueza, glória, aventura e prazer, culminando com a administração de uma enorme porção de terra”. As vicissitudes ocasionadas durante a travessia dos Andes e das pantanosas estepes altas ocasionaram à expedição, de três mil homens, baixas impensáveis.

O sacerdote dominicano Gaspar de Carvajal acompanhou a expedição de Orellana como padre do grupo e escriba e comenta que a decisão de Orellana, de seguir adiante, era devida ao fato de não encontrarem mantimentos e aos perigos representados pelo rio: "[...] porque, mesmo se quiséssemos não era possível voltar a montante, devido à grande correnteza, e tentar ir por terra era impossível por causa da grande fome que padecíamos" (CARVAJAL, 1894, p.8). O relato do frade possui um valor étnico e histórico de suma importância, pois é o único que relata essa primeira imersão no intrincado mundo das águas amazônicas e o primeiro a descrever, mesmo que não profundamente, os povos que ali habitam, seus usos, costumes e línguas. No seu relato Carvajal demonstra o quanto se maravilhou ante a imensidão das águas: “[...] quando vimos à direita entrar um muito grande e poderoso rio, tanto que era maior do que pensávamos, e por ser tão grande o denominamos de Rio Grande” (CARVAJAL, 1894, p.53). Contudo o rio não exerceu outra influência nos viajantes, a não ser aquela de ser o caminho que os reconduziria de volta à terra natal.

Munidos de um barco maior que foi totalmente construído às margens do Amazonas, Orellana e sua tripulação deixam-se levar pelo rio, já sem esperanças de riquezas, almejando apenas não sucumbir ao grande rio. Encontram populações indígenas que os acolhem, os alimentam e outras que os rechaçam, muitas vezes lutando para sobreviver ao massacre ocasionado pelas flechas, algumas das quais eram envenenadas com o curare, cujo processo de produção e uso do veneno os indígenas dominavam perfeitamente. Orellana, como bom comandante, consegue de algum modo interagir com muitas dessas populações e Carvajal anota os nomes dos chefes das tribos com as quais teve contato: Aparia e Machiparo e das populações Omáguas e Paguana, além do referimento às Amazonas. Diferentemente de outros relatórios, o de Carvajal possui certo estranhamento, impondo-se as peripécias de sobrevivência àquelas da procura do ouro, canela e terras, que eram o objetivo principal. Vencidos quase todos os obstáculos, chegam à confluência do Rio Madeira, denominado por Orellana de Rio Grande, ouvem falar de mulheres guerreiras que habitam em aldeias mais ao interior:

Eram mulheres brancas e altas, tinham longos cabelos trançados e enrolados na cabeça, eram muito robustas e estavam nuas, com as partes intimas cobertas, levavam seus arcos e flechas na mão; guerreando tanto quanto dez índios; e, de fato, havia uma que enterrou uma flecha a um palmo de profundidade no bergantim e outras menos profundas, de modo que os bergantins parecessem porcos espinhos. (1894, p. 60) 
O mérito (ou desmérito) do relator é aquele de criar o mito das amazonas americanas, que têm referência nas lendárias mulheres da Cítia que, como estas, viviam em aldeias, onde a entrada de homens era vetada. Quando precisavam de homens para acasalamento, as amazonas tupiniquins assaltavam os territórios vizinhos, capturavam alguns e os levavam para a suas aldeias para cumprirem os fins desejados e depois os deixavam retornar sãos e salvos para suas próprias aldeias. Dissemos desmérito, porque o rio, que porventura poderia chamar-se Rio de Orellana, como alguns o denominaram por algum tempo, mudou de nome, quer essas guerreiras tivessem existido realmente, ou não. O Mar Dulce, o Rio de Orellana passou a chamar-se definitivamente de Rio Amazonas (SMITH, 1990, p.96-97).

Os mistérios do rio sempre fascinaram todos que o conheceram ou ouviram falar dele. Nos europeus do século XVIII e XIX “relativamente famintos de espécimes [...] o Amazonas possuía uma fascinação especial. Era exótico em todos os sentidos, seus pássaros, de coloração mais brilhante, suas frutas, extravagantes" (SMITH, 1990, p.225). Essa atração que o rio manifestava sobre todos que ouviam falar dele produziu sobre o aristocrata francês, membro da Académie, Charles Marie de La Condamine, um efeito fulminante: com os próprios meios, não hesitou a promover, em 1743, a primeira expedição científica pelo Rio Amazonas. Inicialmente, o objetivo de sua viagem era verificar "a verdadeira amplitude de um arco de três graus do meridiano" (LA CONDAMINE, 2000, p.37), determinar o comprimento do pêndulo que bate o segundo e verificar a atração do fio a prumo pela massa semiesférica do Chimborazo, com o objetivo de confirmar ou rebater as previsões de Newton. Contudo a sua curiosidade o impeliu para o Grande Rio, pois seu desejo era fazer o "levantamento da carta de curso de um rio que atravessa vastas regiões, quase desconhecidas de nossos geógrafos" (LA CONDAMINE, 2000, p.32). Segundo Smith (1990), La Condamine pouco pudera investigar, mas, como cientista, "mostrou o caminho" (p.225-226) do rio e da floresta, e sua maior contribuição foi ter servido de estímulo a outros pesquisadores.

$\mathrm{Na}$ esteira das possibilidades de investigação científica de La Condamine muitos outros se seguiram, tais como: Spix e Von Martius (1817-1820), Georg von Langsdorff (1826-1828), Wallace e Bates (1848) e Richard Spruce (1849). Gaetano Osculati, espelhando-se em Orellana e seguindo o exemplo de La Condamine, percorre todo o rio e recolhe grande quantidade de material para estudos posteriores. Ao final da sua viagem compõe a obra Esplorazioni delle Regioni Equatoriali lungo il Napo ed il fiume delle Amazzoni (doravante Esplorazioni), publicada em Milão no ano de 1854.

As etapas percorridas pelos exploradores e cientistas foram de suma importância na compreensão da biodiversidade da Amazônia, no registro dos povos indígenas e ribeirinhos, na explicitação do léxico, sobretudo da fauna e da flora. De fato, nos seus escritos e na sua linguagem é "que se veicula a vida humana nas comunidades sociais. Essa veiculação denota a riqueza do legado tupi na denominação de plantas e animais brasileiros, como um documento vivo dessas influências na constituição do português da América." (NOGUEIRA, 2014, 
p.27). Gaetano Osculati, no seu Esplorazioni, dá a sua contribuição para o conhecimento e compreensão do universo amazônico.

\section{Redescobrindo Gaetano Osculati}

Apesar de ter completado quase 200 anos de sua vinda ao Brasil, Osculati é pouco conhecido em nosso país. Achamos importante compor um capítulo sobre sua biografia e sua navegação no Amazonas, pois deixou uma documentação importante, de caráter científico e etnográfico, desenhos feitos por ele, retratando os índios da Bacia Amazônica, suas casas, enfeites, instrumentos de caça e pesca. Além de viajante era cientista naturalista, antropólogo, desenhista (cf. fig. 1), entomólogo, botânico e cartógrafo.

Fig. 1: Índios Ticuna do Alto Amazonas.

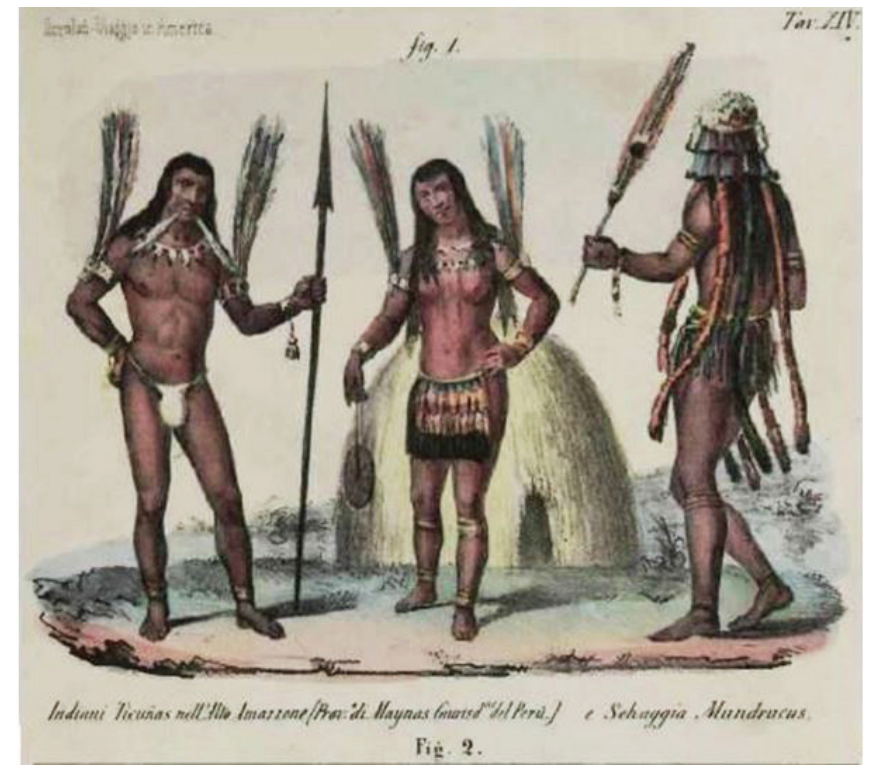

Fonte: Osculati, 1854, Tav. XIV, s.n.

Somando-se a isso, podemos dizer também linguista e lexicógrafo, pois elaborou um pequeno glossário da língua zápara (também chamada kayapwe, falada pelos índios do Peru 
e Equador, hoje quase extinta) e de alguns vocábulos das tribos do Amazonas. No glossário záparo, sistematizou gramaticalmente os verbos, pronomes, artigos, advérbios, frases idiomáticas e pequenos diálogos.

Gaetano Osculati (cf. fig.2), filho de Gerolamo Osculati e di Maddalena Piatti, nasceu no pequeno vilarejo de San Giorgio al Lambro, na Lombardia, no dia 29 de outubro de 1808 e morreu em Milão, em 14 de março de 1894 e está sepultado no Cemitério Monumental desta cidade. Iniciou seus estudos de medicina na Universidade de Milão, mas interrompeu-os para se dedicar às ciências naturais.

Fig. 2: Gaetano Osculati

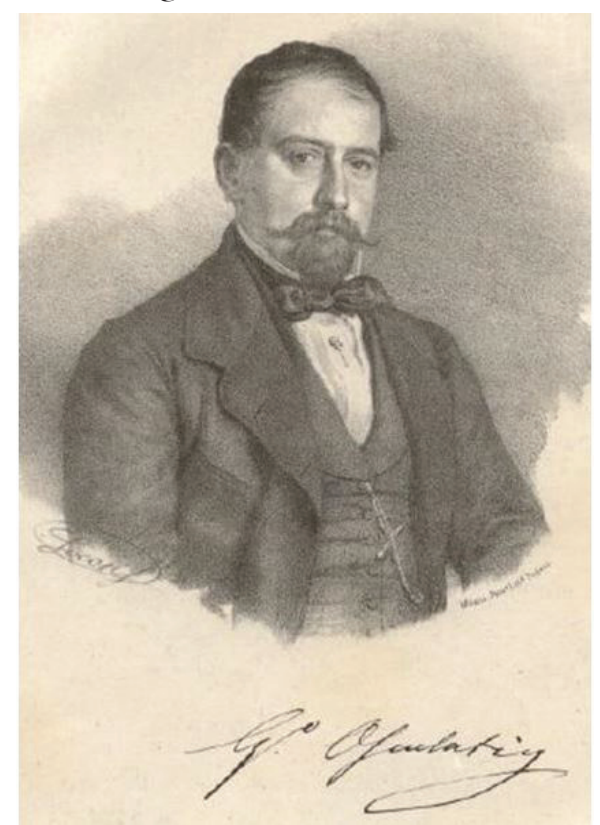

Fonte: G.R.A.L., 2017, p. 2.

Em Livorno, aplicou seu tempo aos estudos de ciências navais e matemática. Em 1831, com 23 anos, diplomou-se como capitão da marinha mercantil e viajou ao Oriente. Ao retornar, deixou o posto e resolveu viajar por conta própria, fazendo isso por diversas vezes. Percorreu os desertos do Egito, da Arábia e Síria, alcançou a Ásia Menor e, em 1834, decidiu conhecer 
a América Latina, viagem esta que durou até 1836. Chegou em Montevidéu e ali se uniu a uma expedição naturalística francesa, com a qual reforçou seus conhecimentos naturalísticos. Viajou até a Colônia de Sacramento, costeou o Rio Negro, desceu o Rio Paraná e chegou em Buenos Aires, partindo em seguida até Mendonza. Em Sacramento, começou a recolher exemplares de pássaros, insetos, fósseis, objetos artesanais, iniciando o que vem a ser a sua maior paixão, a observação da natureza e dos povos que a habitam (G.R.A.L., 2017, p.7-12).

Encontrando-se com seu amigo Felice de Vecchi, no Teatro alla Scala, em Milão, discutiu a ideia de ir novamente ao Oriente. Viajando juntos, alcançaram Constantinopla em 1841, entraram no Curdistão e visitaram algumas das mais importantes cidades da Pérsia, entre as quais Tabriz, Teerã, Persépolis e Shiráz. Chegaram à ilha de Ormus e embarcaram em seguida para Bombaim. Viajaram pela península indiana, conhecendo diversas cidades e em maio de 1842 retornaram passando por Aden, Suez, Cairo, Alexandria, Corfù, Ancona, Trieste e outras.

Essa viagem, além de recolher uma infinidade de materiais, incluindo coleópteros (cf. fig. 3) deu ensejo a Osculati para escrever uma relação de viagem intitulada Note d'un viaggio nella Persia e nelle Indie Orientali negli anni 1841, 1842 (Anotações de uma viagem na Pérsia e nas Índias Orientais nos anos de 1841, 1842).

Fig. 3: Espécimes de coleópteros que levam o nome de Osculati

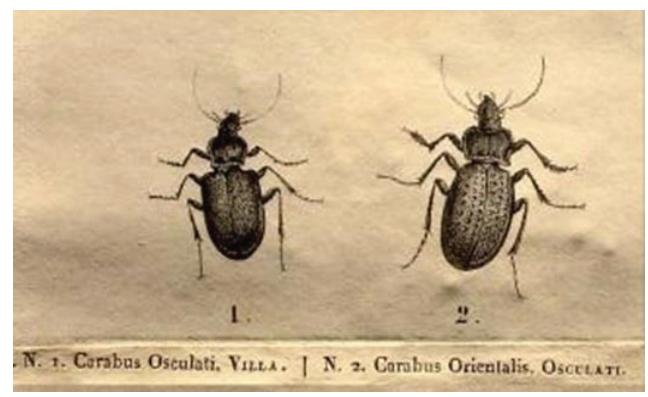

Fonte: G.R.A.L., 2017, p. 29.

Como Antonio Pigafetta, que em 1519 acompanhou Magalhães, Osculati queria fazer uma viagem de circum-navegação e percorrer o Hindustão (antigo nome dado para a região peninsular ao sul da Ásia que compreendia a Índia, Paquistão, Nepal, Bangladesh e Butão), os arquipélagos da Polinésia, e outros lugares que na viagem anterior não teve a oportunidade de conhecer, pois, perto de Algeciras, o navio mercantil no qual viajava se incendiou. Aproveitando-se de um navio da Dalmácia que ia para os Estados Unidos, chegou a Nova York 
e, em seguida, partiu para a Jamaica. Contudo, uma tempestade o fez improvisamente mudar os planos e desse modo, solitário, embarcou na mesma aventura de seu antecessor Orellana que, trezentos anos antes, tinha percorrido os sinuosos caminhos do Rio Napo e Amazonas (cf. fig.4). A diferença é que Orellana, apesar de todas as dificuldades, estava acompanhado pelos seus assessores e ajudantes, e Osculati estava só, contando apenas com sua força e coragem, sem nenhum apoio financeiro.

Fig. 4: Mapa das viagens de Gaetano Osculati nas Américas.

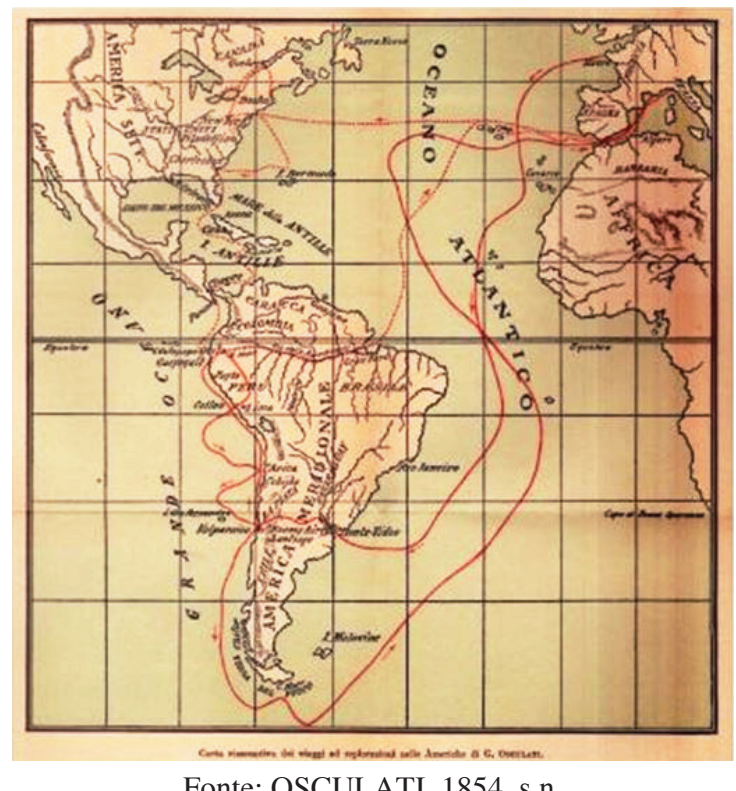

Fonte: OSCULATI, 1854, s.n.

Sua última viagem em 1857 foi ao Egito, Hindustão e China; em Cantão assistiu ao bombardeamento da cidade pelos ingleses, na Guerra do Ópio ou Guerra Anglo-Francês. Infelizmente as crônicas dessa sua viagem perderam-se, não ficando registro algum (TRECCANI, 2017, s. n.). Em 1880, o Imperador Don Pedro II passando por Milão desejou conhecê-lo pessoalmente e agradecido o chama de "O Marco Polo do Brasil". O Rei Humberto I o nominou Cavaleiro da Ordem Mauriciana (Cavaliere dell'Ordine Mauriziana, comenda da Casa de Savoia) em reconhecimento pelos relevantes serviços prestados à causa naturalística. 


\section{Acenos sobre a obra Esplorazioni delle Regioni Equatoriali lungo il Napo ed il fiume delle Amazzoni}

Ao se pensar em viagens, nos vem à memória a ideia de deslocamento espaço-temporal, contudo não é apenas isso. Viajar provoca no viajante transmutações que se apercebem ao longo dos seus relatos, pois a viagem é uma experiência de estranhamento, de sentir-se fora do lugar, em um país estranho com culturas diversas da sua. Afirma Octávio Ianni que "No curso de uma viagem há sempre alguma transfiguração, de tal modo que aquele que parte não é nunca o mesmo que regressa" (1996, p.19). Osculati já no início de seu livro deixa isso claro, ao afirmar que possui "um irresistível desejo de aventuras, a ânsia de enfrentar perigos, de contemplar aqueles lugares e aqueles monumentos que a minha infantil imaginação tinha tantas vezes nos seus sonhos desejado admirar" $(1854$, p.2) e, ao fim da viagem, conforme diz Ianni (1996, p.18), o viajante "à medida que caminha, despoja-se. Quanto mais descortina o novo, o desconhecido, exótico ou surpreendente, mais liberta-se de si, do seu passado [...]. Pode abrir-se cada vez mais para o desconhecido, à medida que mergulha no desconhecido". Viajar é um ato de crescimento intelectual e ao mesmo tempo de transformação de ideias, pois ao conhecer novas culturas, novas realidades o viajante vê sua percepção do mundo modificarse. Mais adiante, Osculati pontua que as viagens não "fossem somente um pasto vão à sua inata curiosidade e irrequietude, mas direcionadas a um outro escopo, fossem um progresso para a ciência e benefício para a sociedade" (op.cit.). Nota-se que após as viagens, existe no autor um outro olhar, já enriquecido pelas múltiplas experiências vividas.

O desejo de Osculati, ao empreender a viagem pelo Amazonas era aquele de partir de Guayaquil e chegar à foz do Rio Amazonas, completando o ciclo de um oceano a outro, e ele o conseguiu, apesar de todos os obstáculos encontrados:

[...] confiando em mim somente e na minha força de vontade [...] vi muitas e muitas vezes pender sobre minha cabeça a morte; [...] sem pão, para o amanhã, no limite das minhas forças e sem armas para defender-me contra as feras [...] tive que lutar contra as armas dos selvagens sem fé [...] e após longos meses passados sempre a céu aberto, nutrindo-me de fruta e carne de tapir e de macacos mal assados, consegui tocar o solo do Brasil, que foi realmente para mim a terra prometida" (OSCULATI, 1854, p.XII).

No relato acima, o nosso viajante expõe as dificuldades encontradas durante seu percurso e um dos fatos mais marcantes que tornaram a viagem uma aventura na selva, foi ter sido roubado pelos seus carregadores contratados em Baeza e deixado só às margens do rio Cosanga, que neste período se encontrava em plena cheia. Ficou preso sem poder mover-se, devido à violência das águas, sobrevivendo com alimentos caçados e um pouco de alimento que os carregadores deixaram. Construiu uma cabana e meios de defesa contra as feras, e 
ali permaneceu por treze dias, correndo constantemente risco de morrer: "Em $1^{\circ}$. de julho, (sétimo dia) tinha quase perdido toda a esperança de sair vivo daquela tetra solidão, pois a enchente continuava com a mesma violência" (OSCULATI, 1854, p.94). Quase sem forças, mal alimentado, decide retroceder até Baeza, correndo o risco de perder-se, como diz ele, no intrincado de rios, pântanos e florestas. $\mathrm{O}$ cientista italiano parte a seguir para Archidona e ali permanece por três meses, não podendo iniciar sua viagem pelo Rio Napo devido ao degelo dos vulcões Antisana e Cotopaxi. Aproveita para fazer pesquisas entomológicas e ornitológicas e cria um herbário de criptogramas e de fúcsias. Descreve minuciosamente os costumes dos índios do lugar: festas, alimentos, caça, pesca, bebidas, festas religiosas, superstições, armas e venenos, divertimentos, a extração de ouro nos rios etc, apresentando em riqueza de detalhes as comunidades indígenas da antiga Província de Quijos. Segue a viagem, desta vez com bom sortimento de canoas e ajudantes pelo Rio Napo.

No rio Napo, entra em contato com a cultura zápara, da qual faz um relato minucioso, inclusive com desenhos e com um glossário da língua. Continuando sua viagem chega ao Rio Amazonas (Alto Amazonas ou Maranõn) e escreve sobre a cultura dos índios ticunas e yaguás e outro grupo indígena que ele denomina Oreckones. Explica, entre outras coisas, o conhecimento e o uso que estes faziam do curare e leva consigo amostras do veneno para experimentos.

No dia 10, parte de Loreto e chega a Tabatinga, em solo brasileiro. Passa por São Paulo de Olivença, Tonantins, Fonte Boa, Tefé, Coari, Manaus, Santarém, Forte Santo Antônio de Gurupá (cf. fig.5) e Belém do Pará.

Fig. 5: Forte de Gurupá no Rio Amazonas, perto da foz do Rio Xingu.

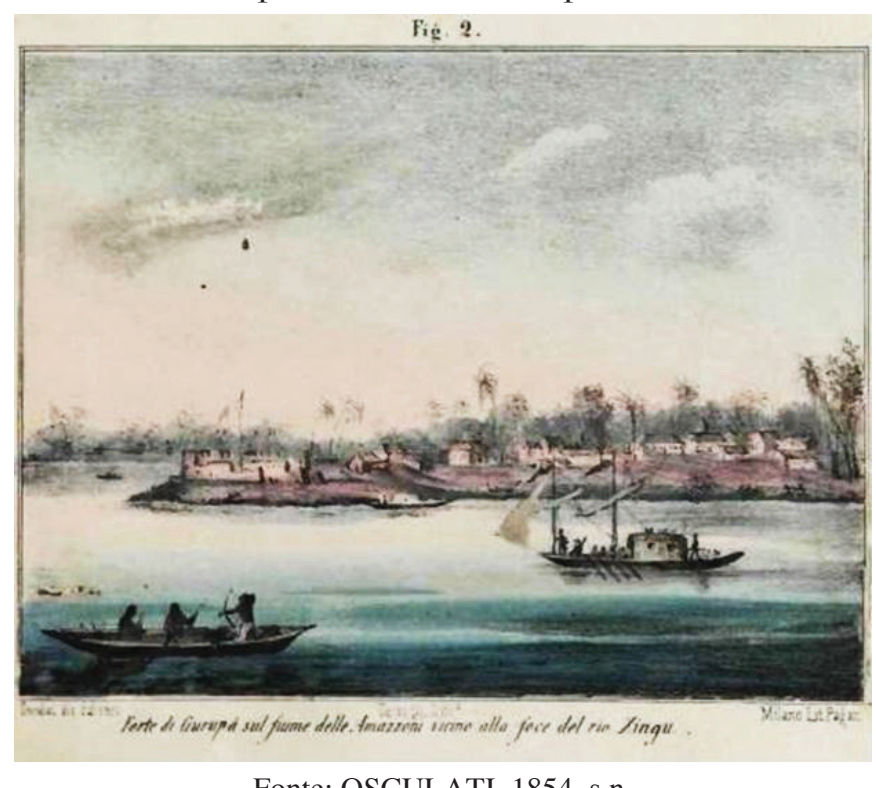

Fonte: OSCULATI, 1854, s.n. 
Relata os costumes dos vários povos amazônicos: em Aratuba, a fabricação da manteiga de tartaruga; em Egas (atual Tefé) comenta a exportação de produtos medicinais, tais como salsaparrilha, copaíba, peixe seco, cacau e a fabricação da farinha de mandioca; fala da destreza dos Cocamas em navegar e construir canoas. Descreve a pesca de lanceada (com redes lançadas) e a fabricação de objetos domésticos feitos de barro e de cuias (Crescentia cujete): “[...] as mulheres dedicam-se à fabricação de odres de terra e à confecção de cabaças, espécie de abóbora, com as quais fazem bacias, conhecidas e postas no comércio com o nome de cuias ou pilche" (OSCULATI, 1854, p.234). Observa o bicho-preguiça, seu habitat e alimentação, compondo desenhos sobre alguns animais que vivem na floresta (cf. fig.6) incluindo tartaruga e cobra.

Fig. 6: Desenhos de animais da Amazônia.

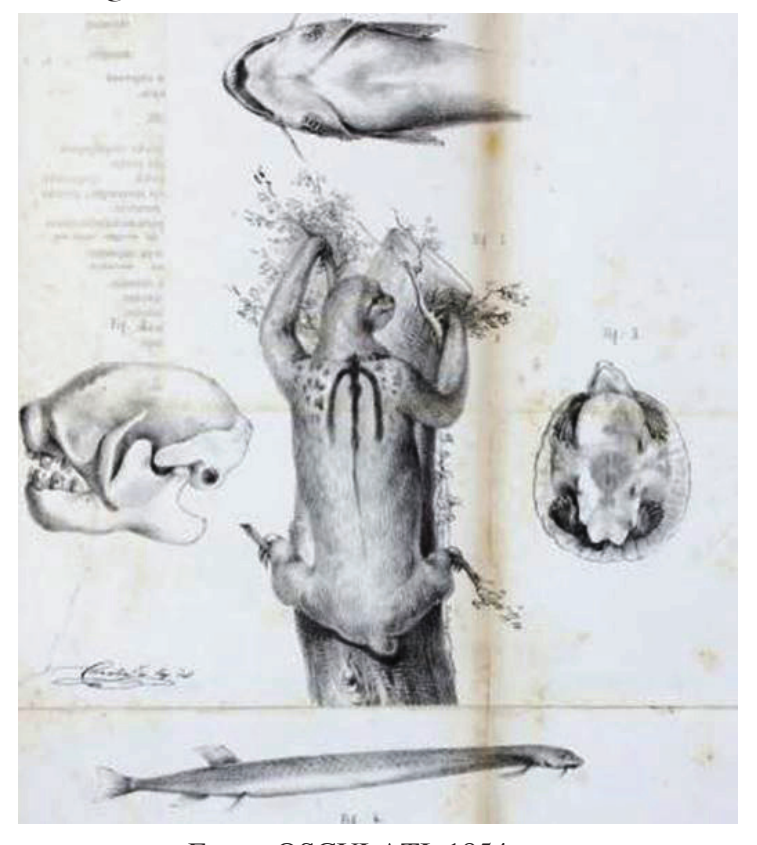

Fonte: OSCULATI, 1854, s.n.

Chega a Manaus, uma cidade habitada por mestiços e indígenas de diversas etnias. Detémse sobre a descrição da onça-preta, das madeiras e da extração da piaçava, cuja produção era exportada para a Inglaterra. Continua a sua viagem, sempre pesquisando sobre a fauna, 
flora, toponomástica, hábitos e populações das cidades que beiram o Rio Amazonas até a foz. Comenta sobre a produção e cultura do guaraná, dos usos que os índios e populações faziam deste vegetal. Tece observações sobre os costumes dos Mundurukus, nação guerreira, que tinha por hábito cortar as cabeças dos inimigos e mumificá-las, e como estas eram utilizadas nas funções religiosas, sendo-lhes atribuídos poderes mágicos.

Finalmente chega a Belém do Pará e ali embarca para a Europa, levando consigo uma variedade de espécimes, armas e objetos das regiões visitadas. Sua viagem exploratória começou em Guayaquil no dia 02 de abril de 1847 e terminou em Belém em 9 de abril de 1848.

O livro Esplorazioni, além do rico material para estudos antropológicos e científicos, é acrescido de:

a) um catálogo das armas, utensílios, ornamentos, utensílios/ferramentas de caça e pesca das várias etnias indígenas que se encontravam às margens do Rio Napo e do Rio Amazonas;

b) desenhos de localidades, montes, populações indígenas e utensílios, obra do autor.

c) um pequeno glossário da língua zápara intitulado Brevi cenni sull'idioma Zaparo (Breve aceno sobre o idioma Zaparo), acrescido de um dicionário e de alguns diálogos necessários à comunicação do autor com os índios;

d) sinopse dos vertebrados: Vertrebratorum synopsis in Museo Mediolanense extantium quae per novam orbem Cajetanus Osculati collegit annis 1846-47-48, speciebus novis vel minus cognitis adjectis nec non descriptionibus atque iconibus illustratis curante Aemilio Cornalia.

Retornando à Italia, Osculati dedica-se a catalogar o resultado da sua viagem e a escrever Esplorazioni. Com os poucos recursos que possuía, sem nenhum auxílio institucional conseguiu reunir um acervo incrível, que depositou no Museu de História Natural de Milão: insetos, animais, espécies botânicas, armas (cf. fig. 6), utensílios, venenos fabricados por diversas tribos etc. (OSCULATI, 1854, p.275-301). 
Fig. 6: Armas dos indígenas do Napo e das margens do Amazonas.

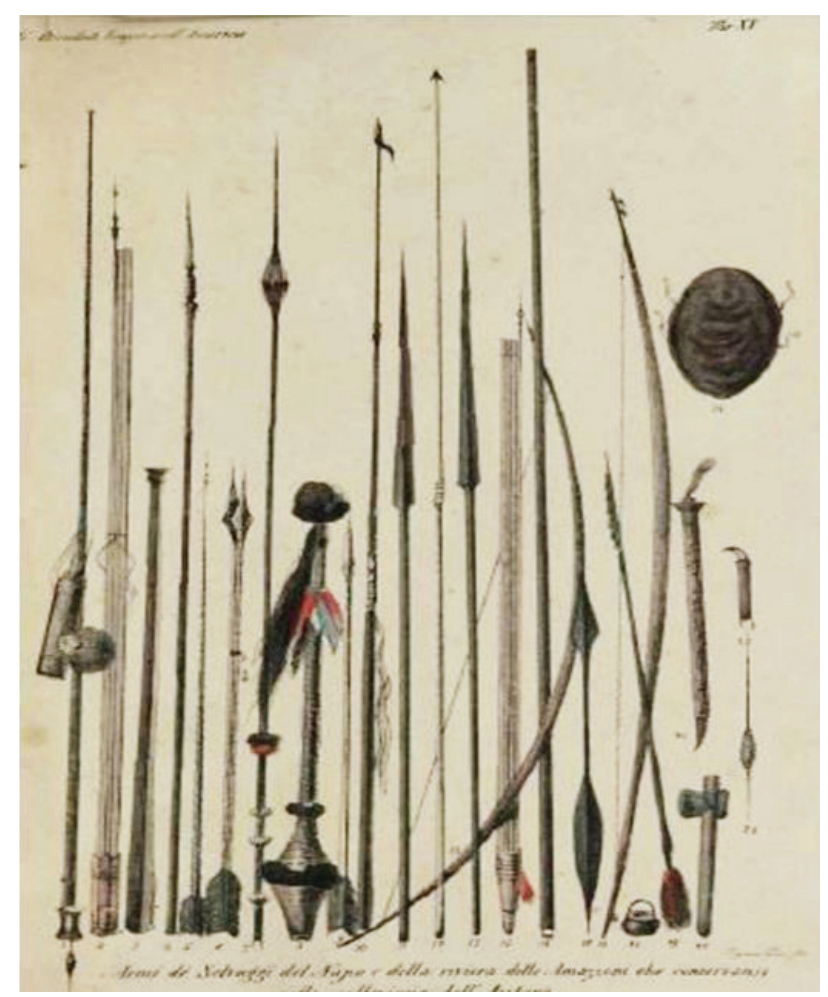

Fonte: OSCULATI, 1854, s.n.

\section{Neologismos e Empréstimos Casuals}

A língua é um organismo vivo que se reproduz e evolui constantemente: seu acervo é ilimitado, pois sempre podemos renová-lo com novas palavras, conquanto se atenda às normas da língua. A esse processo de constante mudança dá-se o nome de neologia que, para Alves (1990, p.5), é um processo de criação lexical e neologismo, o elemento resultante desse processo, isto é, uma unidade léxica que é percebida como nova pela comunidade linguística. Além da criação dentro do próprio sistema, a língua pode ser enriquecida com palavras de outras línguas, os empréstimos. Para Alves (1990, p.72-73) a palavra estrangeira, inicialmente, é percebida pelos falantes como externa ao léxico de sua língua e seu uso determina a incorporação ao léxico ou não. 
A literatura de viagem está repleta de empréstimos de línguas estrangeiras, pois o viajante, ao descrever a realidade dos países visitados, não encontra na sua língua elementos para designar a nova realidade, sobretudo nos países nos quais existiam muitas línguas autóctones, como é o caso das Américas, da África e do Continente Asiático. A difusão de estrangeirismos nas línguas europeias dá-se na época dos descobrimentos (séculos XVI e XVII) e das explorações científicas (séculos XVIII e XIX), quando um grande número de estrangeirismos entrou a fazer parte do léxico dessas línguas como o português, o espanhol e também do italiano e do francês (SCHULTZ, 2016). Para Nunes (1996, p.22), temos nos relatos dos viajantes um difusor desses empréstimos, pois "Fala-se de lugares, plantas e animais nunca vistos, (embora já nomeados pelos autóctones); fala-se de coisas não idênticas, mas semelhantes; constata-se a existência ou inexistência de coisas". Nesse contexto, para que seu leitor possa compreendê-lo melhor, o viajante descreve as unidades lexicais desconhecidas, de modo que o leitor tenha uma ideia da 'coisa'. Contudo, em muitos casos, o viajante e/ou explorador, apenas anota essas palavras novas, mas elas não são dicionarizadas na sua língua, pois servem unicamente para descrever o que viu e dar ao seu texto uma "cor local", como afirma Alves (2010, p. 35). A autora, ao analisar a inclusão de palavras estrangeiras em textos escritos nos diz que há, por parte do autor, um "caráter intencional, voltado para o ludismo ou para a expressividade de um texto" e, ao utilizá-las, o autor torna seu texto diferente e prazeroso.

Às ocorrências que sucedem casualmente em um texto Ivan Klajn (1972) denomina de Empréstimos casual (doravante Ecasual) estrangeirismos que se manifestam esporadicamente. O autor considera que é necessário "[...] reconhecer a existência dos casuals, isto é, das palavras estrangeiras usadas ocasionalmente, na literatura de viagem, nas correspondências do exterior e similares" (KLAJN, 1972, p.22, grifo do autor). A ocorrência de um Ecasual em um contexto histórico/descritivo como dos viajantes e exploradores é meritória, pois assinala a concepção de uma língua em determinado momento. Essa ocorrência foi transcrita em um livro ou relatório e ali permanecerá para sempre, e haverá sempre alguém, em um futuro, que lerá e reconhecerá como um estrangeirismo.

\section{O léxico do portuguès sob o olhar de Gaetano Osculati: elementos da fauna eflora}

Como esta pesquisa tem por objetivo examinar o léxico português inserido incidentalmente ou voluntariamente na obra de Osculati, vamos nos limitar a examiná-lo a partir de sua entrada no Brasil, na cidade de Tabatinga.

O registro desse léxico é fundamental, pois desse modo mantemos a historicidade de um português falado por comunidades isoladas ao longo do Rio Amazonas e que deram à fauna e flora locais os nomes conhecidos pelos índios amazônicos. Assim, encontramos, no 
Esplorazioni, em um único parágrafo, palavras do tupi, do português e topônimos, transcritos em uma amálgama de língua "portugliana", uma mistura de português e italiano, como vemos no exemplo extraído do original de Osculati:

[...] partii da Tonantin e rientrai nel Solimoens, continuando la navigazione sino ad Aratuba, grossa terra allora vuota d' abitatori, dove si fabbrica la manteica od olio di testudine. Si arrivò sull'imbrunire alla fattoria detta jacarè (coccodrillo), nella quale pochi indiani si occupano nella pesca de' lamantini e de' pirarucù (1854, p. 226, grifos do autor).

Como observamos, em apenas algumas linhas encontramos informações várias de como se vivia na Amazônia da primeira metade do século XIX: o autor fala de alimentos comprados na terra, da fabricação da manteiga de tartaruga, produzida nessa região, de uma fazenda onde alguns indígenas pescavam o peixe-boi e os pirarucus. O caboclo e o indígena da Amazônia não vivem na floresta, eles vivem a floresta e o rio. Portanto, suas vidas, seus alimentos e tudo o mais acontece nesse espaço e é nesse ambiente que Osculati recolhe as informações.

Nos relatórios de viagem, a transcrição de uma palavra nova geralmente imita o modelo gráfico e fonético estrangeiro, baseado na correspondência com a própria língua. Vejamos alguns exemplos: "[...] nel quale si fecero abbondanti libazioni di casciassa (aquavite del paese)" (OSCULATI 1857, p. 232), grifo e parênteses do autor). Osculati no Ecasual <casciassa > utiliza duas correspondências em italiano: na representação do som consonantal de $S C I$ em italiano que equivale ao nosso $\mathrm{CH}\left[\int\right]$ e o dígrafo consonantal $S S$, [s] pela não existência do C cedilhado na língua italiana. Outro exemplo “[...] in piccole tribù e Malocche. [...] e venerano i loro payè o indovini” (op.cit. p. 232), grifos do autor). Neste trecho, temos vários exemplos de adaptação à língua italiana: em primeiro lugar destacamos a acentuação das palavras <tribù $>$ e $<$ payè $>$, ambas com o acento grave, pois em italiano se usa acento agudo apenas nas palavras perché e né; na ocorrência <Malocche>, observamos a duplicação da consoante $\mathrm{C}$, muito comum em italiano e o dígrafo $\mathrm{CH}$ para transcrever o [k]. Ainda em <payè > observamos que J é transcrito em [i], pelo não emprego da letra jota na língua italiana. Recorrente em todos os viajantes é a transcrição do plural, sempre finalizado em [i] no masculino "i coati che si pascono di formiche" (op.cit. p. 248, grifo do autor) e [e] no feminino, como em malocche, visto no exemplo acima. Pode ocorrer, ainda que raramente, adaptações morfológicas como no exemplo "il <boiassù> invece il gerarca" (op. cit. p. 248), no qual boiassù em italiano é masculino e em português feminino: a [serpente] boiaçu. Observamos que essas interferências em Osculati não são tantas como em outros viajantes. Atribuímos o fato ao conhecimento que o autor possuía dos nomes científicos e por serem já nomes dados anteriormente por outros viajantes.

Sobre a língua falada pelas comunidades ribeirinhas do Amazonas diz o autor: "A maior parte, porém, daqueles que frequentam os vilarejos, conhece a língua geral (geral), que é a mais usada ao longo do Rio Amazonas, além da língua portuguesa que se fala em cada vilarejo do 
Brasil pelos índios convertidos ao cristianismo" (OSCULATI, 1854, p. 220). Como explica ele, existia uma coexistência pacífica entre a língua nheengatu e o português. A língua geral de Osculati transformou-se no nheengatu da Amazônia e é, segundo Navarro (2016, p. 6-7), ainda falada no vale do Rio Negro, mas não foi língua de nenhum grupo indígena até a chegada dos Europeus à América, porém sua influência foi grande, deixando uma forte herança na toponímia (Manacapuru, Purús, Parintintins), na onomástica (Jacira, Pitanga, Iara), nos nomes das plantas (andiroba, guaraná, piaçaba), nos nomes animais (quati, tatu, mucura) e em outras áreas semânticas, enriquecendo a língua portuguesa com uma variedade sem fim de nomes de origem indígena.

Examinaremos a seguir as ocorrências de elementos da fauna e flora presentes no Esplorazioni que Osculati transcreveu do português e da língua geral. Disporemos as ocorrências no seguinte modo: em primeiro lugar, a ocorrência no autor em negrito, a citação e a ocorrência entre $<\ldots .>$ como se encontra em Osculati (1854), lembrando que nas citações, os grifos em itálico e parênteses são do autor, a seguir o número da página. Dispomos em segundo lugar a ocorrência em negrito, a definição e a etimologia, tendo como base o dicionário Houaiss (2009). Incluímos como Ecasuals da fauna e flora também objetos e produtos que derivam delas, tais como cuia, caucho, etc.

\subsection{Ecasuals da fauna:}

agami: "fra i quali un bellissimo <agami> (psophia crepitans)" (p. 220).

agami: Design. comum às aves gruiformes gên. Psophia, típicas da região amazônica. Etim. orig. obsc., talvez tupi.

boiassù: "il <boiassù>: invece il gerarca" (p. 248).

boiaçu: m. q. SUCURI (Eunectes murinus). Serpente da fam. dos boídeos (Eunectes murinus), encontrada do Norte da América do Sul. Etim. tupi mboyu'su 'nome de várias sp. de cobra, esp. a sucuri', de 'mboya 'cobra' + (gu)a'su 'grande'.

botos: "turbe di delfini $\langle($ Botos $)\rangle$, che davano la caccia ai pesci di cui abbondano quelle acque" (p. 266).

boto: design. comum a várias spp. de mamíferos cetáceos. Etim. b.-tar. buttis 'odre de vinho'.

chandirù: "e alcuni piccoli pesciolini detti <chandirù>" (p. 254).

candiru: peixe (Vandellia cirrhosa) da fam. dos tricomicterídeos, encontrado na Amazônia, Rio de Janeiro e Orinoco. Etim. tupi kandi'ru 'id.' .

caramuru: "potervi rinvenire quei <Caramurù> o Lepidopsiren paradoxa" (p. 253).

caramuru: m. q. PIRAMBOIA. Peixe dipnoico da fam. dos lepidossirenídeos (Lepidosiren paradoxa), encontrado na Amazônia (Lepidosiren paradoxa). Etim. tupi karamu'ru 'moreia'. 
cascabelo: "il <cascabelo> (serpente a sonagli)" (p. 248).

cascavel: serpente venenosa (Crotalus durissus), encontrada do México à Argentina. Etim. provç. cascavel, dim. do lat.vulg. cascabus.

coati: " $\mathrm{i}<$ coati> che si pascono di formiche" (p. 248).

quati: mamífero diurno da fam. dos procionídeos (Nasua nasua). Etim. tupi kwa'ti 'id.'.

guariba: "scimmie vive, una piccola $<$ guariba>" (p. 228).

guariba: bugio ('designação comum', Alouatta fusca e A. caraya). Etim. tupi gwa'riwa 'macaco da família dos cebídeos'.

huackari: "ed un <huackari>” (p. 228).

uacari: design. comum aos macacos, da fam. dos cebídeos, encontrados esp. nas florestas alagadas da Amazônia. Etim. tupi aka'ra 'escamoso, cascudo'.

inanbù: 'd' uova dell' <inanbù>, gallinaceo non dissimile dal pollo” (p. 239).

inhambu: m. q. INAMBU. Design. comum às aves tinamiformes, da fam. dos tinamídeos. Etim. tupi ina' $m b u$ 'ave da família dos tinamídeos'.

jacarè: "in cui stava tirando a terra la rete un enorme jacarè (alligatore)" (p. 234).

jacaré: design. comum aos répteis crocodilianos da fam. dos aligatorídeos. Etim. tupi yaka're.

jaguar: 'L'<jaguar> nero è la specie più feroce, assaltando anche l'uomo" (p. 246).

jaguar: m. q. ONÇA-PRETA. Felino de grande porte (Panthera onca), encontrado do México à Argentina; Etim. tupi ya' gwara'.

manteca: "al modo di preparare la <manteica> o olio di tartaruga." (p. 221).

manteiga: Qualquer óleo ou gordura vegetal ou animal. Nesta ocorrência, trata-se da manteiga/e ou óleo de tartaruga. Etim. orig.duv., prov. pré-romana.

maruins: "orribilmente tormentati dai $<$ Maruins $>$, piccoli moscherini che producono pustole sul corpo e un prurito insopportabile." (p. 240).

maruim: design. comum a diversos mosquitos da fam. dos ceratopogonídeos. Etim. tupi mberu'wi (de mbe'ru 'mosca' + '(w)i 'pequeno').

motucca: "e dalla <motucca>, specie di tafano la cui puntura è dolorosissima" (p. 240).

mutuca: design. comum a todos os insetos dípteros da fam. dos tabanídeos. Etim. tupi mu'tuka.

mucura: "la <mucura>, Yarmadillo o tatoù, il tamandua o formichiere" (p. 238).

mucura: m. q. GAMBÁ. Design. comum aos marsupiais do gên. Didelphis. Etim. tupi mu'kura 'gambá'.

parahuaco: "la scimmia detta <parahuaco> o Phytecia israelita di Spix" (p. 249).

parauaco: design. comum aos macacos amazônicos do gên. Pithecia, da fam. dos cebídeos. Etim. segundo Nascentes, tupi parawa'ku. 
pirapitanga: "varietà che vennero prese, come grossi zurubìn, tombackì, <pirapitanga>, pirarà, o Salmo rhombeus, e alcuni piccoli pesciolini detti chandirù" (p. 254).

pirapitanga: m. q. MATRINX̃̃. Peixe (Brycon hilarii) encontrado nos rios Amazonas. Etim. tupi *pirapïtanga'.

pirarà: "pirapitanga, <pirarà >, o Salmo rhombeus" (p. 254).

pirarara: peixe siluriforme da fam. dos pimelodídeos (Phractocephalus hemiliopterus), amazônico. Etim. tupi *pira'rara.

pirarucù: "grossi pesci conosciuti nel Brasile sotto il nome di <pirarucù>" (p. 219).

pirarucu: Peixe osteoglossiforme (Arapaima gigas), da bacia amazônica. Etim. tupi pirauru'ku < pi'ra 'peixe' + uru'ku 'tintura, almagre'.

pigrisa real: "più singolare è quella detta <pigrisa real>, che ha una larga macchia gialla sul dorso con striscie nere" (p. 236).

preguiça-real: preguiça da fam. dos megaloniquídeos (Choloepus didactylus), encontrada da Colômbia ao Norte do Brasil. Etim. lat. pigritìa,ae 'indolência, preguiça'.

sahui: "La mydas bicolor di Spix o <sahui> de' brasiliani è assai comune" (p. 248).

Sagui: m. q. SAUÍ. Design. comum aos pequenos primatas. Etim. tupi sa'gwi ou sa'gwi 'id.'.

susuruanna: "che al rio Negro chiamano susuruanna è la Felis concolor" (p. 246).

suçuarana: mamífero da fam. dos felídeos (Felis concolor). Etim. segundo Nascentes, do tupi susua'rana 'semelhante ao veado (na cor do pelo)', tb. var. de taturana.

sùcrusgiù: "il <sùcrusgiù> o serpente d'acqua" (p. 248).

sucuri: serpente da fam. dos boídeos (Eunectes murinus) [...] e vive à beira da água ou mergulhada em rios e lagoas. Etim. tupi suku'ri 'id.'

tamandua: "la mucura, l'armadillo o tatoù, il <tamandua> o formichiere" (p. 248).

tamandua: design. comum aos mamíferos xenartros. Etim. tupi tamandu'a.

tatou: "la mucura, l'armadillo o <tatoù>, il tamandua o formichiere" (p. 248).

tatu: design. comum aos mamíferos xenartros da fam. dos dasipodídeos. Etim. tupi ta'tu'.

tombackì: "grossi zurubìn, <tombackì, pirapitanga, pirarà, o Salmo rhombeus" (p. 254).

tambaqui: peixe teleósteo caraciforme da fam. dos caracídeos (Colossoma macropomum), encontrado no rio Amazonas. Etim. tupi *tamba'ki ‘.

toucani: "o col becco dei <toucani>" (p. 231).

tucano (s): design. comum às aves piciformes do gên. Ramphastos. Etim. orig. duv.

urumtùs: "dei rauchi gridi e canti degli <urumtùs>, piurìs, pavas, specie di gallinacei o fagiani le di cui carni sono saporitissime" (p. 239).

urutau: ave da fam. dos nictibiídeos (Nyctibius griseus). Etim. tupi uruta'gwi 'ave da família dos nictibiídeos, coruja', tb. adp. ao port. jurutau e urutago. 
urubutinga: "L'<urubutinga>, ed altri uccelli di rapina, essendone assai ghiotti, se ne stanno continuamente spiando là dove essi fanno il nido" (p. 239).

urubutinga: m.q URUBU-REI. Urubu (Sarcorhamphus papa) que ocorre na América tropical. Etim. tupi uruwu'tinga, < uru'wu 'urubu' + 'tinga 'branco'.

zurubìn: "varietà che vennero prese, come grossi <zurubìn>, tombackì, pirapitanga, pirarà, o Salmo rhombeus, e alcuni piccoli pesciolini detti chandirù (p. 254).

surubim: bagre (Pseudoplatystoma coruscans) encontrado na bacia Amazônica. Etim. tupi suru'wi 'espécie de peixe'.

\subsection{Ecasuals da flora:}

assacù; "Le cime degli alberi, la più parte palmizii <assaccù>, bacabà, miriti, potava, cravo o cannella silvestre" (p. 242).

açacu: árvore de até $30 \mathrm{~m}$ (Hura crepitans) da fam. das euforbiáceas; o fruto dessa árvore. Etim. tupi *asa'ku.

acajoù: 'L'<acajoù>, [...] la maripinina, le cui macchie rassomigliano in tutto alle scaglie della tartaruga" (p. 247).

acaju: m. q. MOGNO-BRASILEIRO. Árvore de até $30 \mathrm{~m}$ (Swietenia macrophylla), da fam. das meliáceas [nativa da Amazônia]. Etim. tupi $a k a$ 'yu 'caju'.

andiroba: "a quello che estraggono dal frutto dell' <andiroba>" (p. 221).

andiroba: árvore de até $30 \mathrm{~m}$ (Carapa guianensis), da fam. das meliáceas, do qual se extrai óleo insetífugo. Etim. tupi ñandïrowa, de ña'ndi 'óleo, azeite' + 'rowa 'amargo'.

bacabà; "Le cime degli alberi, la più parte palmizii assaccù, <bacabà>, miriti, potava, cravo o cannella silvestre" (p. 242).

bacaba: palmeira de até $20 \mathrm{~m}$ (Oenocarpus bacaba); o fruto dessa árvore. Etim. tupi ̈̈wa'kawa (de $\dddot{i}$ 'wa 'fruta' + 'kawa 'gorda, graxa').

calbasse: "di < calbasse>, specie di zucche, colle quali fanno scodelle" (p. 234).

cabaça (s): design. comum a plantas da fam. das cucurbitáceas. Recipiente feito desses frutos. Etim. orig.obsc., talvez pré-romana.

casciassa: "si fecero abbondanti libazioni di <casciassa > (acquavite del paese)" (p. 232). cachaça: aguardente que se extrai, por ferzmentação e destilação. Etim. orig.contrv.

caulciouh: "L'albero che dà la gomma elastica o Caulciouh si trova in copia in tutti questi luoghi” (p. 266).

caucho: árvore que atinge mais de $35 \mathrm{~m}$ (Castilloa ulei), látex de que se faz borracha. Etim. de idioma indígena americano (prov. do Peru) káutxuk, pelo esp. caucho 'id.'. 
cipò: "una specie di tettoja con foglie di palma, tirandone un <cipò>” (p. 239).

cipó: design. comum às plantas lenhosas, trepadeiras, características das matas tropicais. Etim. tupi ïsïpo.

copaiba: "che trovammo intenti a riempiere otri di <copaiba>." (p. 233).

copaíba: design. comum às árvores do gên. Copaifera, da fam. das leguminosas. Óleo extraído da planta. Etim. tupi kopa'ı̈wa 'id.'.

cravo: "Le cime degli alberi, la più parte palmizii assaccù, bacabà, miriti, potava, <cravo $>0$ cannella silvestre" (p. 242).

cravo: flor do craveiro (Dianthus caryophyllus). Etim. lat. clavu(s), i 'prego, cravo'.

cuyas: "e poste in commercio sotto il nome di <cuyas>". (p. 234).

cuia (s): fruto da cuieira; recipiente ger. ovoide feito desse fruto. Etim. tupi 'kuya.

guaranà: Il <guaranà> è un composto di fruita silvestre preparato massime col Sorbillum brasiliense (specie di ciliegio" (p. 263).

guaraná: rbusto escandente de até $10 \mathrm{~m}$ (Paullinia cupana), da fam. das sapindáceas. Etim. segundo JM, tupi wara'ná.

haubá: "<L'hauba> trovasi di due qualità" (p. 247).

ubá: m. q. UVÁ. Árvore (Myrcia acrantha) da fam. das mirtáceas, cuja madeira é usada na carpintaria; Etim. prov. tupi 'ïwa 'árvore'.

huassucù: "lo ammazzano a colpi di azza, o avvelenandolo coll'Huassucù" (p. 263).

açacu: árvore de até $30 \mathrm{~m}$ (Hura crepitans) da fam. das euforbiáceas [A planta exsuda látex venenoso]. Etim. tupi *asa'ku.

igname: "Spogliata della pelle la radice dell'<igname>, la pestano e la riducono in pasta". (p. 235).

inhame: m. q. UAÇACU. Design. comum a algumas plantas da fam. das aráceas. Etim. afr. de orig.contrv.

imbauba: "osservai questi animali sugli alberi d'<imbauba>, cibandosi di quelle foglie tenere e dei germogli"'(p. 236).

imbaúba: design. comum às árvores do gên. Cecropia. Etim. tupi amba'̈̈wa 'id.' .

itauba: L'<itauba> di due sorla, gialla e nera, che serve ai naturali per la costruzione delle canoe" (p. 247).

itaúba: árvore (Phoebe semicarpifolia) da mesma fam., nativa do Brasil (AM). Etim. tupi *ita'ïwa < i’ta 'pedra' + ïwa 'planta, árvore'.

macucù: " vernice è preparata coi sughi dei frulli dell'albero detto <macucù>” (p. 235).

macucu: árvore de até $25 \mathrm{~m}$ (Aldina heterophylla) da fam. das leguminosas. Etim. voc. tupi 'nome de plantas da fam. das leguminosas e das rosáceas'.

mandioca: "mettendola in commercio sotto il nome di farina di <mandioca>" (p. 235).

mandioca: arbusto (Manihot esculenta) da fam. das euforbiáceas, nativo da América do Sul. A raiz dessa planta. Etim. tupi mandi'oka 'id.' . 
masaranduba: "la <masandaruba> a chiazze nere e bianche" (p. 247).

maçaranduba: árvore de grande porte (Manilkara excelsa), nativa da Amazônia, de madeira violácea. Etim. tupi mosarandi'̈̈wa 'id.'.

miriti; "Le cime degli alberi, la più parte palmizii assaccù, bacabà, <miriti >, patavà, cravo o cannella silvestre" (p. 242).

buriti: m. q. MIRITI. Design. comum a plantas dos gên. Mauritia, Mauritiella, Trithrinax e Astrocaryum, da fam. das palmas. Etim. tupi *mbïri’ tï 'espécie de palmeira'.

mururè: Le mirabili guarigioni che assicuransi ottenute col $<$ Mururè $\rangle$ (detto anche mercurio vegetale)" (p. 261).

mururé: planta (Ludwigia repens) da fam. das onagráceas, nativa de regiões tropicais. Etim. tupi *muru'ri 'plantas de folhas grandes e largas'.

patavà: "Le cime degli alberi, la più parte palmizii assaccù, bacabà, miriti, <patavà̀, cravo o cannella silvestre" (p. 242).

batauá: palmeira de até $25 \mathrm{~m}$ (Oenocarpus bataua), nativa do Peru, Colômbia, Venezuela, Guianas e Brasil (AM e PA) Etim. tupi bata'wa ou pata'wa 'palmeira que dá palmito'.

pao d'arco: "il <pao d'arco $>$, servibile per far archi, essendo dotato di molta elasticità e pieghevolezza"(p. 247).

pau-d'arco: design. comum a várias árvores e arbustos da fam. das bignoniáceas. Etim. Não apresenta.

roucù: "a bizzarri disegni con suchi vegetabili d'indaco, di <roucoù>”. (p. 235).

urucum: árvore pequena (Bixa orellana) da fam. das bixáceas; substância extraída dos frutos dessa árvore, rica em bixina, de que se fazem corantes. Etim. tupi uru'ku 'id.' .

seringa: "a far <siringas> o scarpe di gomma elástica" (p. 217).

seringa: Nome da goma-elástica extraída de várias árvores do gên. Hevea. Etim. gr. sûrigks,iggos 'caniço talhado'.

tanibuca: "la <tanibuca>, per costruire le grandi barche" (p. 247).

tanibuca: árvore de até $20 \mathrm{~m}$ (Buchenavia capitata) da fam. das combretáceas, nativa das Antilhas e da América do Sul. Etim. segundo Nascentes, tupi tani'buka.

tapioca: "farina bianca di <tapioca> negli occhi, nella bocca, sulla testa" (p. 250-251).

tapioca: fécula comestível, extraída das raízes da mandioca. Etim. Nascentes registra o tupi tïpï’og 'sedimento, coágulo da mandioca crua coalhada'.

Encontramos em nossa pesquisa um total de 31 Ecasuals referentes à fauna e 28 da flora, perfazendo um total de 59 empréstimos neológicos utilizados por Osculati no seu livro. Por não encontrar no dicionário Houaiss alguns Ecasuals citados pelo autor, não os registramos, como, por exemplo, pavas, piurìs etc. Observamos que muitas vezes o Ecasual registrado se assemelha mais ao nome tupi do que ao nome em português. Isso deve-se, talvez, pelo 
contato que o viajante teve com os indígenas, muito mais do que com brasileiros que falavam o português.

Além dos elementos da flora, a obra de Osculati é repleta de topônimos amazonenses, sobretudo nome de cidades, rios e lagos, sendo a maioria topônimos indígenas. Relaciona as etnias que encontrou no seu percurso, dados que se prestam a novas pesquisas, sobretudo os nomes dos lugares mencionados que talvez hoje não existam mais com a mesma denominação.

\section{Considerações finais}

O Rio Amazonas sempre exerceu e exerce ainda um poder de atração muito grande nas pessoas e vê-lo sob o olhar de Osculati foi uma experiência fascinante. Com ele sentimos as agruras da viagem, mas também vimos a beleza da flora, fauna e costumes dos povos que vivem ao longo do Rio-mar. Comprovamos que o autor se apropria de palavras do português, majoritariamente de etimologia tupi, e as transcreve em italiano, obedecendo à grafia da sua língua (coati, guaranà, boiassù, casciassa etc.).

Observamos que alguns desses Ecasuals estão já dicionarizados na língua italiana, com algumas mudanças gráficas em relação ao encontrado em Osculati: acagiù (acaju), cacciu (caucho), manioca (mandioca), copaiba, andiroba, igname (inhame), guaraná, tatou (tatu), casciassa (cachaça) e tamanduá (SCHULTZ, 2007). Constatamos que existe uma estreita ligação entre o nomear e o narrar, pois ele concentra no narrar suas impressões e conhecimentos sobre a coisa nomeada: “osservai questi animali [preguiça] sugli alberi d'<imbauba>, cibandosi di quelle foglie tenere e dei germogli” (OSCULATI, 1854, p.236), dá sua contribuição e conhecimento de um explorador ao descrever a alimentação e o modo como se comporta a preguiça e com sua obra imortaliza o Amazonas do século XIX, seus povos, sua crenças, suas culturas e seus falares.

\section{Referências}

ALVES, I. M. Neologismo. São Paulo, Ática, 1990.

Neologia e neologismos do português brasileiro contemporâneo. In: Lima-Hernandes, M.

C.; Chulata, K. de Abreu (orgs). Língua portuguesa em foco: ensino-aprendizagem, pesquisa e tradução. Lecce, Pensa Multimedia Editores, 2010, v. 1, p.35-44.

CARVAJAL, G. de. Descubriemento del Rio de Las Amazonas. Sevilla, Imprenta de E. Rasco, 1894.

G.R.A.L. Gruppo di Ricerca Archeostoriche del Lambro. Gaetano Osculati. Mostra Storica. Museo Civico "Carlo Verri", Biassono. Disponível em: <http://www.museobiassono.it/Italiano/index. php?page=/Italiano/Mostre/GaetanoOsculati/Pagina03.html> Acesso: 20 de março de 2017.

IANNI, O. A Metáfora da Viagem. Revista Cultura Vozes, Petrópolis, n.2, p.3-19, março-abril 1996. 
HOUAISS, Antonio. Dicionário Eletrônico Houaiss da Língua Portuguesa. Rio de Janeiro, Objetiva, 2009. CD-ROM.

KLAJN, I. Influssi inglesi nella lingua italiana. Firenze, Leo S. Olscki Editori, 1972.

LA CONDAMINE, Charles-Marie de. Viagem na América meridional descendo o rio das Amazonas. Brasília, Senado Federal, 2000, p.14. Disponível em: <https://www2.senado.leg.br/bdsf/bitstream/ handle/id/1045/580837.pdf?sequence=4>. Acesso em: 19 de março de 2017.

NAVARRO, E. de Almeida. Curso de Língua Geral. (Nheengatu ou tupi moderno). São Bernardo do Campo, Paym gráfica e editora, 2016.

NOGUEIRA, J. Castro. O legado tupi na fauna e na flora acreanas: contribuição para o ensino da língua portuguesa. In: Nascimento, L.M.; Lima, S.S. (orgs.). Caleidoscópios da cultura brasileira. Rio de Janeiro, Letra Capital, 2014, p.26-37.

NUNES, J. H. Discurso e instrumentos linguísticos no Brasil: dos relatos de viajantes aos primeiros dicionários. São Paulo, 1996. Tese (Doutorado em Linguística). Instituto de Estudos da Linguagem, Universidade Estadual de Campinas, São Paulo, 1996.

OSCULATI, G. Esplorazioni delle Regioni Equatoriali lungo il Napo ed il fiume delle Amazzoni. Milano, Presso i Fratelli Centenari, 1854.

SCHULTZ, B. Socreppa. O conhecimento de mundos desconhecidos: palavras e coisas do português na literatura dos viajantes italianos. Cascavel, Edunioeste, 2016.

Brasileirismos e portuguesismos incorporados ao léxico da língua italiana: análise de campos léxico-conceptuais. São Paulo, 2007. Dissertação (Mestrado em língua italiana). Faculdade de Filosofia, Letras e Ciências Humanas, Universidade de São Paulo.

SMITH, A. Os conquistadores da Amazônia. Quatro séculos de exploração e aventura no maior rio do mundo. Tradução de M. T. M. Cavallari. São Paulo, Best Seller, 1990.

TRECCANI. Dizionario bibliográfico. Disponível em: http://www.treccani.it/enciclopedia/gaetanoosculati_(Dizionario-Biografico)/. Acesso em 16 de março de 2017.

Recebido em 18/09/2017

Aprovado em 22/11/2017 